\title{
Fungicide resistant Trichoderma strains causing compost infection in shiitake production
}

\author{
Turóczi, Gy. ${ }^{1}$, Kovácsné Gyenes, M. ${ }^{2}$, Vajna, L. ${ }^{3}$ and Balázs, S. ${ }^{4}$ \\ ${ }^{I}$ Szent István University, Faculty of Agriculture and Environmental Protection, Gödöllö \\ ${ }^{2}$ Vegetable Crops Research Institute Co. Kecskemét \\ ${ }^{3}$ Research Institute of Plant Protection, Budapest \\ ${ }^{4}$ Szent István University, Faculty of Horticulture, Dept. of Vegetable and Mushroom Growing \\ 1118 Budapest, Ménesi u. 44
}

\begin{abstract}
Summary: Trichoderma infection represents the major problem of shiitake production in the growing house of the Research Institute at Kecskemét. Heavy infections occur mainly on the compost before spawn run. All the isolated strain belongs to the species Trichoderma harzianum, but morphology of the colony indicates that there are more strains liable for the infection. Source of infection remained unclear but the Trichoderma strains can be considered as weed moulds rather than true pathogens of shiitake. All the Trichoderma isolates showed unusual high degree of resistance to fungicides.
\end{abstract}

Key words: Trichoderma, mushroom, shiitake, infection

\section{Introduction}

Shiitake fungus (Lentinus edodes) is grown at the Research Institute on wheat straw as substrate. Occasional but heavy Trichoderma infections have become the major problem of the production in recent years.

Trichoderma infection is worldwide a common and increasing problem in mushroom production. However, it seems that the situation is not the same with Agaricus as with Lentinus. In the Agaricus production a new and serious epidemic started in the eighties (or maybe somewhat earlier), first in Europe (Ireland) and later in North America and Australia (Seaby, 1998). On the other hand, Trichoderma infection has since long been a well-known problem in cultivation of Lentinus edodes (Komatsu, 1976), and Trichoderma infections of Lentinus species are frequent in the nature as well. What is more, Trichoderma preparations have been successfully used for the biological control of wood decaying fungi, among others Lentinus species (Bruce et al, 1984, Bruce \& Highley, 1991).

Due to an extensive international research program, Trichoderma pathogens are best known and most thoroughly studied on Agaricus. Most of the information obtained there is probably applicable in shiitake production as well.

The origin of Trichoderma infection is mostly unclear. Compost itself can be an important starting point of the disease. The basic ingredients of any kind of compost (e.g. straw, sawdust) probably are contaminated with Trichoderma spores. Although proper heat treatment should eliminate germs, there always can be such parts in the compost volume where the peak temperature is not high enough to kill all the spores. It has been proven that even a small number of starting Trichoderma colonies can cover large areas of the bags or trays in a short time, causing serious yield loss (Seaby, 1998).

Air-borne spores are the most typical source of Trichoderma (and other microbial) infections. From the compost production to the fruiting houses, Trichoderma spores are everywhere present. In fact, the incidence of these is much lower than that of some other fungi, but even a few spores can initiate a serious infection. In the air of Japanese Lentinus fruiting houses, Penicillium spores were predominant with more than $70 \%$ of the total colonyforming unit (cfu) while Trichoderma spores reached less than $2 \%$. But the occurrence of Trichoderma spores (i.e. the frequency of the isolation regardless of the small cfu) was among the highest with more than 70\% (Togashi et al, 1997) and thus far exceeded the rest of other possible pathogens.

It is strange how polyethylene bags used for compost increase the possibility of aerial infection. Opening the bags creates an electrostatic charge. This was shown to attract dust with Trichoderma (and obviously other) spores (Seaby, 1996, Terras \& Hales, 1995). Moreover, the almost sterile surface of the new bags, and higher $\mathrm{CO}_{2}$ concentration within polythene bags enhances the growth of Trichoderma (Seaby, 1998)

Further sources of infection are: the water used in fruiting houses, casing soil (of Agaricus), compost amendments. Even spawn was found to carry Trichoderma spores when it was not properly prepared or treated. Spores can be carried also by animals (insects, mites, mice), on the workers' clothing and on machinery (vehicles, buildings, etc). It was found that the equipment of mushroom growing farms is heavily infected with Trichoderma, although the colonies are microscopic (invisible) and can be detected with microbiological methods only (Seaby, 1998). 
There are more Trichoderma species which are capable to grow on the mushroom compost or to infect fruiting bodies. Due to the obscure Trichoderma taxonomy until the eighties, most of the mushroom-infecting strains were identified as $T$, viride PERS.: Fr., $T$. koningii OUD, or mainly $T$. harzianum RIFAI. The recent extensive study on the Agaricus-infecting $T$. harzianum species-aggregate (which is far the most important either as mushroom pathogen or biocontrol agent) has revealed, that this single taxon comprises at least four biological species (Seaby, 1998). Such revision of Lentinus-infecting Trichoderma strains is not yet available.

The control of disease caused by Trichoderma is far not solved today. The control methods include both prevention and chemical control. Some strains of Lentinus might be less susceptible than others (Ohmasa et al, 1995), but considering the wide variety of infecting Trichoderma strains, breeding a really resistant Lentinus strain will be a hard job.

Careful preparation and handling of compost is as important as is the regular desinfestation of buildings, shelves, machinery, etc. Some additives in the compost can help the protection but may also have an adverse effect. For instance lime as an additive prevents Trichoderma infection in Pleurotus but not in Lentinus since the latter is as sensitive to lime as Trichoderma itself (Liu \& Sun, 1988).

The possibility of chemical control is restricted since most of the fungicides are even as toxic for the mushroom itself as are for the pathogens. Mainly two benzimidazole fungicides (benomyl and carbendazim) and prochloraz are world-wide used. In Hungary, only the latter one is registered in Agaricus but not in Pleurotus or Lentinus. Usually high final concentrations are needed (100-200 ppm in the compost, Huang et al, 1988), and all the above fungicides are considered today as dangerous and far not environment friendly

\section{Material and method}

Sampling and isolation. Samples for isolation were collected from the following origins: (1) Wheat straw stockpile for compost preparation (the wheat straw used for this purpose is good quality, but the field conditions where it was grown (e.g. fungicidal treatments) are not recorded.); (2) moistened wheat straw ready for heat treatment; heat-treated straw from the centre (3) and lateral (4) part of the heating equipment; (5) spawned compost. Samples also were taken from the infected parts of the compost bags at the beginning of the colonisation period (just after spawning) and after spawn run, from fruiting bags. Infected fruiting bodies also have been collected. All samples were stored in plastic bags until processing, in refrigerator. Straw samples were then shaken in distilled water, and the suspension was diluted 10 fold repeatedly to $10^{-4} .100 \mu \mathrm{l}$ from each dilution has been plated on suitable agar media.

Media and culture conditions: for isolation, nutrient and malt extract agar (MEA) has been used. The latter was amended with $100 \mathrm{ppm}$ of chloramphenicol. Fungal isolates were grown on potato dextrose agar (PDA) and MEA, under conditions described by Bissett (1991/a). Cultures are stored at $5{ }^{\circ} \mathrm{C}$ on MEA slant agar covered with sterile paraffin oil. All media have been prepared according to Dhingra \& Sinclair (1985).

Identification. Trichoderma strains were identified according to the monographs of Rifai (1969) and Bissett (1991/a, b).

In vitro antagonism. Interaction of the Trichoderma and mushroom isolates was studied on PDA (a) and on moistened and sterilised wheat grains (b).

(a) strains were inoculated on the opposite margin of PDA plates, mushroom cultures a week before Trichoderma.

(b) $13 \mathrm{~mm}$ diameter test tubes open at both end were filled with water soaked wheat and then were placed in $16 \mathrm{~mm}$ test tubes, plugged and sterilised. After sterilisation Trichoderma and Lentinus strains were inoculated on the opposite end of tubes

Fungicide resistance. Tested fungicides were benomyl, carbendazim (both benzimidazole) and prochloraz (Fundazol 50WP, Kolfugo 25WP and Sporgon, respectively). Stock solution of $10000 \mathrm{ppm}$ active ingredient was prepared in acetone and was added to PDA to achieve the final concentrations of 5, 25, 100 and $500 \mathrm{ppm}$, respectively. $5 \mathrm{~mm}$ diameter agar blocks from freshly growing margins of Trichoderma and shiitake colonies were placed on such poisoned agar plates. Growth of colonies was compared to the normal growth on non-poisoned PDA.

\section{Results}

Wheat straw samples from the stockpile to the period of after-sterilisation had never been sterile (Table I). Stored and moistened straw had almost the same fungal and

Table 1 Colony forming units in the wheat straw (cfu/g dry weight)

\begin{tabular}{|l|c|c|c|c|c|}
\hline & Stockpile & Moistened straw & $\begin{array}{c}\text { Middle of the heating } \\
\text { equipment } \\
\text { (1) }\end{array}$ & $\begin{array}{c}\text { Lateral part of the heating } \\
\text { equipment } \\
\text { (4) }\end{array}$ & $\begin{array}{c}\text { Compost after } \\
\text { spawning } \\
\text { (5) }\end{array}$ \\
\hline Fungal propagules & $\sim 1 \times 10^{5}$ & $3 \times 10^{4}$ & $3 \times 10^{2}$ & $4.3 \times 10^{4}$ & $2 \times 10^{3}$ \\
\hline Bacterial propagules & $\gg 10^{5}$ & $>10^{5}$ & 0 & $>10^{5}$ & $>10^{5}$ \\
\hline Dominating fungi & $\begin{array}{c}\text { Penicillium spp. } \\
\text { Alternaria spp. }\end{array}$ & $\begin{array}{c}\text { Alternaria } \text { spp. } \\
\text { (+ yeasts) }\end{array}$ & $\begin{array}{c}\text { Geotrichum } \text { sp. } \\
\text { Alternaria spp. } \\
\text { Penicillium } \text { spp. }\end{array}$ & $\begin{array}{c}\text { Penicillium spp. } \\
\text { Alternaria } \text { spp. } \\
\text { (+ yeasts) }\end{array}$ \\
\hline
\end{tabular}


bacterial cfu numbers, as well as the compost from the lateral part of the heating equipment and the compost after spawning. Only the straw from the central part was less infected. In this sample practically there were no bacteria and the number of fungi was much lower. It was very conspicuous that all samples were dominated by one - or few - type of fungal colonies.

Early infection of the compost bags (i.e. just few days after spawning) was general, when it occurred at all. It means that some batches were entirely free of Trichoderma infection while others were not. We could find no connection with environmental or other factors explaining this variability. Characteristic green patches of Trichoderma appeared everywhere, but the growth seemed to be only superficial, under the polyethylene. When compost bags have been infected with Trichoderma, the Lentinus fails to colonise the compost so no caps can be expected.

Late infection after spawn run has never been so general, only a smaller part of the compost bags was affected. Further difference from the early infection was that only small areas were covered by the Trichoderma colonies. On the other hand, Trichoderma could be isolated not only from the surface but they invaded the stroma of Lentinus edodes deeper, causing a soft, dark brown rot. Occasionally, fruiting bodies were also infected and in these cases, the stroma of the caps was damaged as well. Generally, late Trichoderma infections in the growing house of Kecskemét are considered far less dangerous than early ones.

Identification of Trichoderma isolates. In our earlier studies we have identified both Trichoderma hamatum (BON.) BAIN. and T. harzianum on the fruiting bodies of $L$. edodes (not published). In recent samples, all the isolates showed the typical microscopic characteristics of the latter (T. harzianum) species: tough, regularly branching conidiophores with short, straight phialides, $3-5$ of them arranged in whorls. Conidia were green, short ellipsoid, 2.8-3.2 $\mu \mathrm{m}$ long (Rifai, 1969, Bissett, 1991/b). On the contrary, colony morphology of individual isolates was not the same in every case. Some produced sparse aerial mycelium on MEA while others formed rather thick, almost stromatic colonies. Isolates of colonies displayed different morphology frequently derived from the same sample.

In vitro interaction of Trichoderma isolates and Lentinus edodes. There was no detectable inhibition zone between any of the Trichoderma isolates and Lentinus edodes strains on PDA. Shiitake produced dark brown pigment on the reverse side of colonies in the neighbourhood of Trichoderma colonies. Microscopic investigation of the interaction revealed that both Trichoderma and Lentinus hyphae died in the interaction zone (the cytoplasm of the hyphal tips became granulated). Some of the Trichoderma also produced chlamydospores which is the indication of unfavourable conditions. Any mark of direct parasitism (mycoparasitism) or of stronger antibiotic effect could not be detected. On contrary, Trichoderma isolates grew much faster on wheat grains than Lentinus but no any kind of direct parasitism or expressed antagonism at the meeting point of two colonies was detected either by macroscopic or microscopic investigation.

Effect of fungicides. All the ten studied Trichoderma isolates from shiitake grew equally well on media containing 5 or $25 \mathrm{ppm}$ of either benomyl or carbendazim. Higher concentration of these fungicides caused only weak inhibition with a maximum of $50 \%$ depression of colony size at the very high concentration of $500 \mathrm{ppm}$ (Figure 1). Control Trichoderma strains (soil isolates) were more sensitive. Their growth was already repressed at the concentration of $25 \mathrm{ppm}$. Prochloraz was much more effective, initially there were no detectable growth of Trichoderma strains even at the lowest concentration. After ten days of incubation some of the Trichoderma isolates also started to grow on media containing prochloraz even up to $100 \mathrm{ppm}$, and although much slower than the control, the colonies had covered the entire Petri-dish within a week.

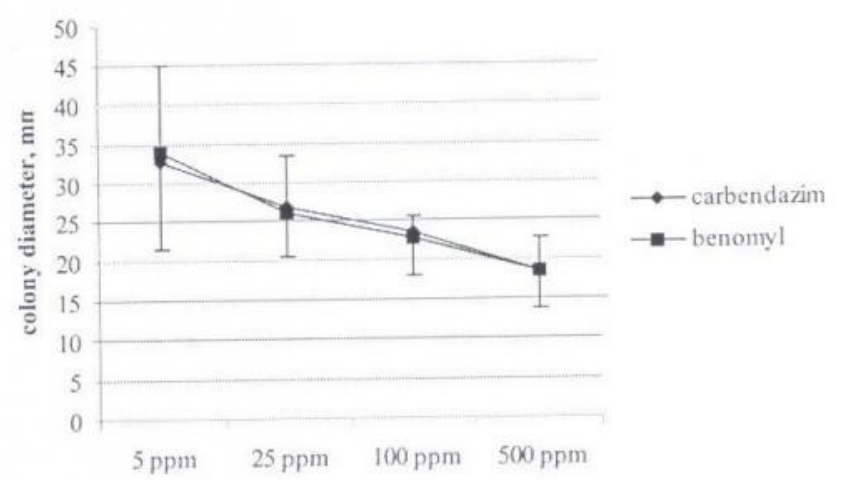

Figure $I$ Colony size of Trichoderma isolates on media containing various concentrations of carbendazim and benomyl (average of seven isolates). Vertical bars show the $95 \%$ confidence interval, upper ones for benomyl and lower for carbendazim.

\section{Discussion}

Although the propagation of fungi and bacteria during the storage in refrigerator can not be excluded, the wheat straw used as compost had always been heavily contaminated with micro-organisms. On the other hand we were not able to detect the presence of Trichoderma in the straw samples. Dominating fungi were typical representatives of air-borne contamination. We assume that Trichoderma spores are always present in the buildings where compost is prepared and these spores (some of them surviving even the sterilisation process) are the origin of later infections.

Occasional but heavy infection just after spawning of the compost indicates that the Trichoderma strains are good competitors in colonisation of the wheat straw. The later decline of Trichoderma infections after spawn run and rare infections on caps together suggest that these Trichoderma strains could be only secondary pathogens of Lentínus. It can be concluded that - as it was found in many other cases Trichoderma in shiitake production can be considered as weed moulds rather than true pathogens (Seaby, 1998). 
Although all the isolates have been identified as $T$. harzianum, the observed variation of the colony morphology proves that there is not a single specialised strain which infects the compost. On the other hand the high level of fungicide resistance found in the isolated strains could be the result of a selection due to the extensive use of such type of chemicals. It should be also mentioned that some correlation between high cellulase activity (which is of course necessary for straw colonisation) and benomyl resistance has been found earlier (Baker, 1991).

The observed fungicide resistance also explains the low efficacy of the chemical control experiments (actually no any fungicide is registered in shiitake production in Hungary). Effective control measures should be further searched for, possibly including biological control methods.

\section{References}

Baker, R. (1991): Induction of rhizosphere competence in the biocontrol fungus Trichoderma. pp. 221-228. in Keister, D.L. and Cregan, P.B. (eds.) The rizosphere and plant growth Kluwer Academic Publishers

Bissett, J. (1991/a): A revision of the genus Trichoderma: II. Infrageneric classification. Canadian Journal of Botany, 69: $2357-2372$.

Bissett, J. (1991/b): A revision of the genus Trichoderma: III. Section Pachybasium. Canadian Journal of Botany, 69: 2373-2417.

Bruce, A., Austin, W.J. \& King, B. (1984): Control of growth of Lentinus lepideus by volatiles from Trichoderma. Transactions of the British Mycological Society 82: 423-428.

Bruce, A. \& Highley, T.L. (1991): Control of growth of wood decay basidiomycetes by Trichoderma spp. and other potentially antagonistic fungi. Forest Products Journal, 41: 2.
Dhingra, O.D. \& Sinclair, J.B. (1985): Basic Plant Pathology Methods. 355 pp. CRC Press, Boca Raton, Florida

Huang, D.B., Deng, M.H., Gao, C.X., He, X.J. \& Gao, X.N. 1988. Study on the control of moulds on Lentinus edodes. Fujian Agricultural Science and Technology, 4: 16-18

Komatsu, M. (1976): Studies on Hypocrea, Trichoderma and allied fungi antagonistic to shiitake, Lentinus edodes. Report of the Tottori Mycological Institute 13: 1-113.

Liu, X.X. \& Sun,T.Y. (1988): The role of lime in the selective compost for edible fungi. Zhongguo-Shiyongjun-Edible-Fungi-ofChina, 1: 14-16.

Ohmasa, M., Tsunoda, M., Hiraide, M. \& Elliott, T.J. (1995): A method to assay varietal difference of disease resistance of Lentinus edodes against Trichoderma spp. Mushroom Science, 14: 579-585.

Rifai, M. A. (1969): A revision of the genus Trichoderma. Mycological Papers, 116: 1-56.

Seaby, D.A. 1996. Investigation of the epidemiology of green mould of mushroom (Agaricus bisporus) compost caused by Trichoderma harzianum. Plant Pathology, 45: 913-923.

Seaby, D. (1998): Trichoderma as a weed mould or pathogen in mushroom cultivation, p 267-287. In: Harman, G.E. and Kubicek, C.P. (eds): Trichoderma and Gliocladium, Vol. 2., Taylor and Francis, London-Bristol.

Terras, M.A. \& Hales, D.F. (1995): Red pepper mites are vectors of Trichoderma. Mushroom Science, 14: 485-490.

Togashi, I., Itoh, K., Gisusi, S. \& Harada, A. (1997): Distribution of airborne fungi in fruiting houses for the sawdustbased cultivation of Lentinus edodes. Journal of the Hokkaido Forest Products Research Institute, 11: 1-4. 